\title{
TYUlENEVA Vera, Cuatro viajes a la Amazonía boliviana
}

\section{Diego Villar}

\section{OpenEdition \\ Journals}

\section{Edición electrónica}

URL: https://journals.openedition.org/jsa/11998

DOI: 10.4000/jsa. 11998

ISSN: 1957-7842

Editor

Société des américanistes

\section{Edición impresa}

Fecha de publicación: 20 diciembre 2011

Paginación: 413-418

ISSN: 0037-9174

Referencia electrónica

Diego Villar, "Tyuleneva Vera, Cuatro viajes a la Amazonía boliviana», Journal de la Société des américanistes [En línea], 97-2 | 2011, Publicado el 22 diciembre 2011, consultado el 04 septiembre 2022. URL: http://journals.openedition.org/jsa/11998 ; DOl: https://doi.org/10.4000/jsa. 11998

Este documento fue generado automáticamente el 4 septiembre 2022.

All rights reserved 


\title{
TYULENEVA Vera, Cuatro viajes a la Amazonía boliviana
}

\author{
Diego Villar
}

\section{REFERENCIA}

TYULENEVA Vera, Cuatro viajes a la Amazonía boliviana, Foro boliviano sobre medioambiente y desarrollo, La Paz, 2010, 155 p. + 30 p. de pl., bibl., ill., photos, cartes

1 Este libro reúne cuatro investigaciones recientes sobre la Amazonía boliviana que, además de ser interesantes en sí mismas, despliegan aproximaciones - algunas veces oblicuas y otras más directas - a la saga del Paititi, la célebre « noticia rica » que tanta tinta hizo correr desde el siglo XvI hasta nuestros días. Vera Tyuleneva lamenta que el Paititi sea un tema injustamente excluido de la investigación científica seria por su amplia repercusión literaria y periodística, por lo general sensacionalista y carente de documentación. Al mismo tiempo, no admite el dogma textualista de que las fuentes reflejan la subjetividad, la ideología o el contexto de los autores más que los hechos concretos. Sin negar las inexorables distorsiones que implica cualquier exégesis, reivindica la posibilidad de una lectura responsable que reconstruya parte del pasado mediante el estudio de las fuentes históricas; en suma, plantea sin ambages que se puede ir más allá del Paititi como mito o cifra del imaginario utópico para indagar fructíferamente en el Paititi como topónimo, como nombre de un cacique o como ámbito geográfico específico.

El primer viaje (2004) es una descripción de varios sitios arqueológicos y del arte rupestre de las márgenes de los ríos Madera y Negro en los departamentos de Beni y Pando. Con un lenguaje simple y preciso se describen los «afiladores» tallados en roca de Villa Bella, los yacimientos de "tierra negra " y los fragmentos de hachas de piedra de las inmediaciones de Guayaramerín, los petroglifos de Cachuela Chocolatal y del Río Negro, así como también los ejemplares hallados en tierras concesionados a la empresa maderera « Pacahuaras », que comparten una iconografía común con los petroglifos del 
río Abuná: espirales, círculos concéntricos, círculos con centros puntuados, líneas onduladas paralelas, etc.

3 El segundo viaje (2005) se realiza en el marco del proyecto boliviano-japonés « Mojos ». Si bien se trata en principio de un recorrido arqueológico prospectivo de localidades como Beni, Trinidad, Exaltación, San Lorenzo o San Ignacio de Mojos, se advierte una mayor inflexión etnológica de la argumentación: así, la interpretación de los restos materiales de Cerro Chico, Cerro de la Cruz, San Carlos o el lago Rogoaguado se liga fluidamente con la etnografía mojeña, con determinados términos cayuvavas, con el imaginario colonial del Paititi y con el folclore regional (espíritus, brujos, «tigresgente » o la misteriosa « ruta de los jesuitas » por la que supuestamente huyeron los soldados de Cristo hacia los Andes acarreando fabulosas riquezas). Resultan particularmente interesantes algunas asociaciones entre los datos arqueológicos y la afamada creencia en la Loma Santa, próspero paraíso mojeño accesible a los nativos pero cerrado a los blancos, cuya busca resurge cíclicamente en pueblos como San Lorenzo y San Ignacio de Mojos (Lehm 1999). Tyuleneva entrevistó algunos participantes de la última migración hacia Loma Santa en las décadas de 1960 y 1970, destacando tanto las contradicciones entre el discurso milenarista y la moderna educación laica como también las simetrías respecto de los cultos cristianos. Por otro lado, conjetura que la idea misma de la Loma Santa tiene su génesis en la legendaria «tierra sin mal » que atravesó los llanos de Mojos con las migraciones guaraníes, sintetizándose en el camino con ciertos resabios de la leyenda del Paititi (Combès 2011).

4 Los dos últimos trabajos son más extensos, y a la vez más interesantes por la articulación sistemática de datos de diversas procedencias. El tercer viaje (2006) es una busca explícita del Paititi en los alrededores del lago Rogoaguado que intenta reconciliar dos aspectos diferentes del imaginario de la tierra rica: por un lado, que el término aparece en las fuentes como topónimo al este de los Andes o como nombre de un líder asociado con la prosperidad e incluso, a veces, con los metales preciosos; por el otro, que surge como destino último de las expediciones incaicas hacia la selva referidas por Sarmiento de Gamboa, Murua o Garcilaso.

5 La autora describe en detalle el informe de Juan Álvarez de Maldonado (1906), que, entre 1567 y 1569, desciende a la selva por el Madre de Dios y recorre fatigosamente la margen occidental del Beni mencionando entre otros grupos a los "Chunchos", "Moxos", "Guarayos ", «Pacajes ", "Yuquimonas », «Guanapaonas ", «Aravaonas », "Toromonas", "Corivas», " Marupas» y «Cabinas». Sin embargo, pronto surgen problemas con otras parcialidades que apoyaban a una expedición rival que provenía de Camata, liderada por Gómez de Tordoya, y el cacique "aravaona» Tarano termina apresando a Maldonado y poniendo fin a la expedición, aunque muestra clemencia ante Maldonado y le permite regresar al Cusco. Para Tyuleneva, lo más significativo de este emprendimiento trunco es la referencia a una " laguna del Paitite ", a la cual se accedería por el río Madre de Dios. Otra referencia importante es la Relación del teniente Juan Recio de León en las primeras décadas del xVII, que recorre los ríos Tuichi y Beni encontrándose con unos « anamas » que le hablan del « gran Paytiti » y le enseñan como prueba algunas perlas y conchas de nácar. Tyuleneva también recuerda la florida tradición jesuítica sobre el Paititi y, en particular, los viajes del padre Agustín Zapata a los « cayubabas », cuyo jefe era un « viejo venerable» llamado Paititi. Luego analiza el reciclaje de estas informaciones en las compilaciones de Cosme Bueno, Fernando Rodríguez Tena y el franciscano Nicolás Armentia, un buen conocedor de la zona que 
opinaba que el territorio del Paititi se ubica en el triángulo comprendido entre los ríos Beni, Mamoré y Yacuma (Armentia 1905, p. 237). Tampoco olvida las exploraciones decimonónicas del prefecto José Agustín Palacios, las investigaciones del historiador argentino Roberto Levillier, del arqueólogo finlandés Marti Pärsinnen, de la arqueología de los llanos de Mojos (Denevan, Erickson, Dougherty y Calandra, Prümers) e incluso de Harold Key sobre la lingüística cayuvava - de hecho, siguiendo la pista de Zapata, uno de los argumentos del libro es que la palabra « Paititi » podría ser de origen cayuvava.

Tyuleneva confiesa que al principio siguió a pie juntillas las intuiciones de Levillier, que ubicaba el Paititi en Rondonia, en la Sierra de Paresis (Levillier 1976; Tyuleneva 2003); sin embargo, una relectura de las fuentes pronto la convenció de que la famosa « laguna del Paitite» es el actual lago Rogoaguado. Para probarlo analiza diversos aspectos de aquellas conchas que producen perlas referidas por Recio de León (Leila blainvilliana), al parecer frecuentes en dicho lago. Sin embargo, persiste el hecho de que el mismo no tiene una comunicación directa con el río Madre de Dios - como si sugería que la había Maldonado. Apoyada en evidencia arqueológica recogida en sitios como Coquinal, Chacos, Piraquinal, San Carlos, Nuevo Paraíso, Villa Delicia, Gualaguagua, La Avenida, Loma Guamisa, y también en las colecciones de los museos de Reyes y Santa Ana de Yacuma, Tyuleneva ensaya entonces posibles soluciones para el dilema, y sugiere finalmente una comunicación pretérita entre el Madre de Dios y el Rogoaguado a través del río Tapado, que luego se habría convertido en un pantanal y finalmente dejó de ser navegable.

7 El último viaje (2007) enfoca la atención sobre Apolobamba. Ubicada entre Larecaja y Carabaya, se trata de una región estratégica por su ubicación geográfica entre las tierras altas y bajas, con lo cual devino históricamente epicentro de un intenso juego de conexiones entre el piedemonte andino y los llanos amazónicos. Tyuleneva describe las posibles influencias serranas a nivel arqueológico en la fortaleza fronteriza de Ixiamas, o en las tumbas, muros, piezas metálicas y "canchones " y otras estructuras pétreas de localidades como San Buenaventura, Maije, Motacusal y Bella Altura. A la vez, es consciente de que el nexo con el imaginario incaico muchas veces tiene más que ver con fantasías populares que con la realidad (p. 138).

Lo más interesante del capítulo, sin embargo, es el análisis de las probables influencias andinas en la cultura de los tacanas de Tumupasa y San Buenaventura. Además de las referidas entradas de Álvarez Maldonado y Juan Recio de León, Tyuleneva revisa la gesta de Pedro Anzúrez (1538-1539), los reportes del fraile agustino Bernardo Torres (1657) sobre los uchupiamonas, arabaonas y eparamonas que encuentra junto a los aguachiles y a los lecos, y los posteriores viajes de Evans o el franciscano Armentia. Este último advierte agudamente las mutaciones semánticas del término " chuncho »: si en algunas fuentes la palabra se aplicaba "á todo salvage que no fuese Chiriguano » (Armentia 1905, p. 116), desde mediados y fines del XVII otros testimonios la emplean para referirse más específicamente a los tacanas (ver Saignes 1981). Otro punto de interés del artículo es la traducción de algunos mitos tacanas compilados por Karin Hissink y Albert Hahn a comienzos de los 1950s: si bien existe una traducción castellana del segundo tomo de su etnografía (Hissink y Hahn 2000), publicada originalmente en alemán, jamás se tradujo el primer tomo.

9 Entre los rastros de influencias serranas, Tyuleneva destaca la «interferencia » del quechua y aymará en el tacana (por ejemplo, en los numerales, en topónimos como Mamacona, Jatuncama, Jatunari o Saparuna, en términos como « huaca », « yanacona » o 
el mismo "tacana»). Se detiene particularmente en la etimología del nombre del principal cerro de Tumupasa, Caquiahuaca (" huaca que truena ", « huaca del sonido del rayo ", " huaca que tose », etc.), que ocupa un lugar destacado no sólo en la clásica etnografía de Hissink y Hahn sino incluso en los arquetipos trans-culturales del controvertido Mircea Eliade (1971, pp. 249-251). La autora despliega numerosas versiones de la narrativa sobre el Inca forastero, pródigo en sirvientas, poderes y riquezas, que sin embargo resulta sexualmente ambiguo y termina castigando la curiosidad de los antepasados sobre su sexualidad maldiciéndolos y huyendo hacia las montañas, no sin antes dejar los caminos de piedra. Al hacerlo abre una interesante discusión: si debe entenderse necesariamente que estos ecos incaicos reflejan un contacto directo de los tacanas con el Tawantisuyu o bien reflejan reverberaciones orales transmitidas a la usanza estructuralista - lo más probable, no obstante, es que ambas alternativas no sean incompatibles (ver Brohan y Herrera 2009). En este punto también cobran sentido las nutridas alusiones orales a los cerros, con su arquitectura interna, sus riquezas inimaginables y su sociabilidad misteriosa, con evidentes resonancias de los apus andinos (Ricard Lanata 2007). También habría rastros serranos en los especialistas rituales, tanto en su denominación (yanaconas) como en sus técnicas (el uso ritual de hoja de coca, etc). Más discutible, en cambio, se revela la cuestión de las relaciones ritualizadas con los dueños de las cosas (plantas, animales, ríos, etc.), con los cuales los hombres deben establecer ciclos de pagos, ofrendas y reciprocidades - de hecho, podría argumentarse que la estructuración de la naturaleza en términos de una propiedad de los dueños es un fenómeno tan amazónico como andino, y que en todo caso la cuestión no revela gran cosa sobre la especificidad cultural y étnica de Apolobamba.

Como sea, los méritos del libro son muchos. Tal vez el más evidente sea la cantidad de información. Cuatro viajes a la Amazonía boliviana es una obra curiosa porque a la vez es prudente y polémica. El eclecticismo de la argumentación es llamativo, y la propia autora, que pide indulgencia por su « diletantismo », la compara de hecho con los relatos decimonónicos por su tendencia voraz a incorporar cuanto dato, episodio o detalle caiga en sus manos (pp.15-16). La interdisciplina suele ser una virtud farisaica, mucho más pregonada que practicada: no es el caso de este libro. Para echar luz sobre un escenario abigarrado, casi mitológico, chispeante de rumores, de aventureros ávidos de oro y jesuitas ávidos de almas, de indígenas volátiles, de noticias, riquezas y redenciones efímeras, Tyuleneva se nutre de los datos de la arqueología, la lingüística, la etnología o la etnohistoria, y también de los aportes menos previsibles de la hidrografía, la cartografía o aun la misma biología. Lo hace reconociendo que algunos de los trabajos compilados son más definitivos que otros (p. 15), que contienen lagunas y errores (p. 17), que hay detalles que no encajan en las hipótesis (p. 49), y sin escatimar - lo que es poco frecuente en una obra con pretensiones etnológicas - aquellas ocasiones en las cuales los datos provienen de un único día de trabajo en determinada población (p. 20). Podríamos agregar, finalmente, que en todo momento la prosa de Tyuleneva es llana, clara, directa, que evita las opacidades superfluas y se atreve a especular sin caer por ello en diatribas teóricas ni en abstracciones inverosímiles. 


\section{BIBLIOGRAFÍA}

\section{ÁLVAREZ DE MALDONADO Juan}

1906 « Información de méritos y servicios de Juan Álvarez Maldonado, titulado descubridor de Nueva Andalucía, Chunchos, Mojos y Paititi, acompañada de una relación de su descubrimiento. Años 1570 a 1629 ", in Víctor Maúrtua, Juicio de límites entre el Perú y Bolivia. Prueba peruana presentada al gobierno de la república argentina, 6, Henrich y Co., Barcelona, pp. 17-68.

\section{ARMENTIA Nicolás}

1905 Descripción del territorio de las misiones franciscanas de Apolobamba por otro nombre Frontera de Caupolicán, Tipografía artística, La Paz.

BROHAN Mickaël y Enrique HERRERA

2009 « Prólogo de los editores », in Alfredo Tabo Amapo, El eco de las voces olvidadas. Una autoetnografía y etnohistoria de los cavineños de la Amazonía boliviana, IWGIA, Copenhague, pp. 12-45.

coMBÈs Isabelle

2011 « Pai Sumé, el Rey Blanco y el Paititi », Anthropos, 106 (1), pp. 99-104.

ELIADE Mircea

1971 « South American High Gods. Part II », History of Religions, 10 (3), pp. 234-266.

HISSINK Karin y Albert HAHN

2000 Los tacana: datos sobre la historia de su civilización, ABCOB, La Paz.

\section{LEHM Zulema}

1999 Milenarismo y movimientos sociales en la Amazonía boliviana. La búsqueda de la Loma Santa y la marcha indígena por el territorio y la dignidad, CIDDEBENI/ OXFAM/APCOB, Santa Cruz.

LEVILLIER Roberto

1976 El Paititi, el Dorado y las Amazonas, Emecé, Buenos Aires.

\section{RICARD LANATA Xavier}

2007 Ladrones de sombra. El universo religioso de los pastores del Ausangate (Andes surperuanos), IFEA/ Centro « Bartolomé de Las Casas », Lima.

\section{SAIGNES Thierry}

1981 «El piedemonte amazónico de los Andes meridionales: estado de la cuestión y problemas relativos a la ocupación en los siglos XVI y XVII », Bulletin IFEA, 10 (3-4), pp. 141-176.

\section{TYULENEVA Vera}

2003 « La Leyenda del Paititi: versiones modernas y coloniales », Revista Andina, 36, pp. 191-211.

\section{AUTORES}

\section{DIEGO VILLAR}

CONICET, Argentina 